\title{
ePAT: A simple method to tag adenylated RNA to measure poly(A)-tail length and other 3' RACE applications
}

\author{
AMREI JÄNICKE, JOHN VANCUYLENBERG, PETER R. BOAG, ANA TRAVEN, and TRAUDE H. BEILHARZ ${ }^{\mathbf{1}}$ \\ Department of Biochemistry and Molecular Biology, Monash University, Clayton, Victoria 3800, Australia
}

\begin{abstract}
The addition of a poly(A)-tail to the $3^{\prime}$ termini of RNA molecules influences stability, nuclear export, and efficiency of translation. In the cytoplasm, dynamic changes in the length of the poly(A)-tail have long been recognized as reflective of the switch between translational silence and activation. Thus, measurement of the poly(A)-tail associated with any given mRNA at steady-state can serve as a surrogate readout of its translation-state. Here, we describe a simple new method to $3^{\prime}$-tag adenylated RNA in total RNA samples using the intrinsic property of Escherichia coli DNA polymerase I to extend an RNA primer using a DNA template. This tag can serve as an anchor for CDNA synthesis and subsequent gene-specific PCR to assess poly(A)-tail length. We call this method extension Poly(A) Test (ePAT). The ePAT approach is as efficient as traditional LigationMediated Poly(A) Test (LM-PAT) assays, avoids problems of internal priming associated with oligo-dT-based methods, and allows for the accurate analysis of both the poly(A)-tail length and alternate 3' UTR usage in 3' RACE applications.
\end{abstract}

Keywords: mRNA polyadenylation; alternative polyadenylation; translational control; LM-PAT assay

\section{INTRODUCTION}

The poly(A)-tail is involved in all major functions of eukaryotic mRNA, and addition of this tail is the final quality control step that nascent mRNA undergo prior to nuclear export (Proudfoot et al. 2002). In this context, it is thought that the poly(A)-tail promotes circularization of the RNA molecule into a closed-loop configuration that promotes translation initiation (Sachs and Varani 2000). At synthesis, the length of the poly $(\mathrm{A})$-tail is generally uniform in any given system, with the absolute length being species-dependent; in yeast and mammalian cells, this is $\sim 90$ and 250 adenosine residues, respectively. However, in the cytoplasm, the steadystate length distribution of poly(A)-tails can vary dramatically for transcripts of different functional classes due to differential, transcript-specific deadenylation rates, a disconnect between deadenylation and decapping and/or stabilization during translation (Decker and Parker 1993; Brown and Sachs 1998; Beilharz and Preiss 2007). For example, targeted deadenylation is provoked by microRNA binding (Beilharz et al. 2009; Eulalio et al. 2009; Fabian et al. 2009) or RNA binding proteins. Compensatory and activating cytoplasmic adenylation can further modulate the polyadenylation state

\footnotetext{
${ }^{1}$ Corresponding author.

E-mail traude.beilharz@monash.edu.

Article published online ahead of print. Article and publication date are at http://www.rnajournal.org/cgi/doi/10.1261/rna.031898.111.
}

of the transcriptomes of many eukaryotes (Rouhana and Wickens 2007; Burns et al. 2011). Finally, eukaryotic cells also employ the ancient, prokaryotic function of RNA adenylation to destabilize mitochondrial, structural, and noncoding RNA (Slomovic et al. 2010; for review, see Eckmann et al. 2011). We have previously shown that the adenylation state of the transcriptome is highly correlated with other gene expression parameters, such as ribosome occupancy and protein abundance (Beilharz and Preiss 2007; Lackner et al. 2007), which has led us to propose that the measurement of mRNA poly(A)-tail length can serve as a surrogate for translation-state measurements.

There are several well-characterized methods for measuring poly(A)-tail length. The most direct method is the combined use of RNase $\mathrm{H}$ digest ( \pm Oligo $\mathrm{dT}$ ) and highresolution Northern blot (Sippel et al. 1974; Decker and Parker 1993; Sheets et al. 1994). In our own laboratory, we have made extensive use of the Ligation- Mediated Poly $(\underline{\mathrm{A}})$ Test (LM-PAT) assay developed by the Strickland laboratory (Salles and Strickland 1995; Beilharz and Preiss 2007; Lackner et al. 2007; Beilharz et al. 2009; Traven et al. 2009; Dagley et al. 2011). Finally, several laboratories have used T4 RNA ligase approaches to either circularize mRNA (Couttet et al. 1997) or, more recently, to ligate adaptors to the $3^{\prime}$ end of mRNA (Charlesworth et al. 2004). While each of these assays can serve to measure poly(A)-tail length, each has its own limitations. High-resolution Northern 
blots are labor-intensive and require a lot of RNA, the LM-PAT assay has low-resolution and a tendency toward exaggerated apparent short-tailed mRNA, and adaptorligation approaches are relatively inefficient. We sought to develop an assay that is simple, high-resolution, and efficient for measuring the poly(A)-tail of mRNA and to unambiguously assign the 3' UTR of specific transcripts. Our assay is based on the use of Klenow polymerase to extend the 3' termini of specific RNA molecules with dNTPs (Huang and Szostak 1996). We describe how this intrinsic activity (Okazaki and Okazaki 1969) can be harnessed to tag the $3^{\prime}$ end of RNA molecules as an extension-mediated poly(A)tail length measurement as well as for other applications that require $3^{\prime}$-end labeling.

\section{RESULTS AND DISCUSSION}

\section{A simple method for $3^{\prime}$-tagging of adenylated RNA}

The extension $\underline{\operatorname{Poly}}(\underline{\mathrm{A}})$ Test (ePAT) approach is a simple two-step assay conducted in one reaction tube that relies on the intrinsic property of the Klenow polymerase to extend RNA molecules with dNTPs from a annealed oligonucleotide DNA template in standard reverse transcription buffers (Fig. 1A). Increasing the temperature to $55^{\circ} \mathrm{C}$ prior to addition of reverse transcriptase ensures that only the DNA oligos that have annealed to an extended 3' terminus have a melt-temperature sufficiently high to prime reverse transcription. This eliminates unwanted priming from internal poly(A)-tracts. Subsequent amplification using a gene-specific forward primer and a universal reverse primer results in PCR amplicons that reflect the length distribution of the poly(A)-tail on endogenous mRNA. To calculate the actual length of the poly(A)-tail, a separate "TVN-PAT" reaction can be performed which reports the size of the amplicon with an invariant 12-(A) poly(A)-tail, irrespective of the actual poly(A)-lengths in the sample. The TVN-PAT cDNA is prepared using the identical primer sequence as for ePAT except for the addition of two 3' variable bases $\mathrm{V}$ and $\mathrm{N}$ (where $\mathrm{V}$ is $\mathrm{A}, \mathrm{G}$, or $\mathrm{C}$, and $\mathrm{N}$ is any base). These variable bases lock the primer to the polyadenylation site during reverse transcription (Beilharz and Preiss 2009).

To test the fidelity of ePAT in reporting poly(A)-tail length over a range of RNA concentrations, we prepared serial $(1 / 2)$ dilutions of total yeast RNA to spike into a fixed concentration of Human (HeLa) total RNA. The yeast total RNA was isolated from cells that had undergone a 10-min incubation with galactose. At this early time point after galactose induction, GAL10 shows a uniform length of $\sim 40$ adenosine residues. $A P Q 12$, on the other hand, is not a galactose-responsive gene and shows a "smear" of amplicons reflecting both new and aged transcripts (Fig. 1B). The poly(A)-tail reported by ePAT is invariant across the concentration range tested. Furthermore, densitometry shows that the method is quantitative within the quantitative

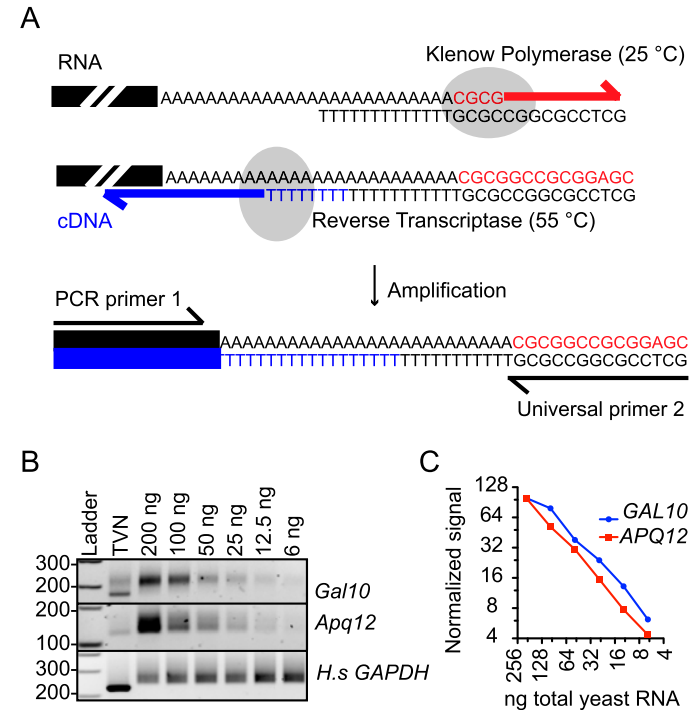

FIGURE 1. (A) Schematic illustration of the ePAT approach. In the first step of the assay, a DNA oligo is annealed to adenylated RNA via an oligo-(dT) stretch. The addition of Klenow polymerase and dNTPs to the reaction results in templated extension of the $3^{\prime}$ terminus of the poly(A) tract to fill in the recessed end. The second step of the assay is performed at $55^{\circ} \mathrm{C}$ to ensure that the primer used for extension can only remain annealed to end-extended molecules and not internal poly(A) tracts through oligo-(T) alone. PCR amplification of cDNA using a gene-specific primer (primer 1) and a universal reverse primer (primer 2) results in a range of amplicon sizes that reflects the position of the gene-specific primer relative to the poly(A) site and the length distribution of poly(A)-tails in the sample. (B) Serially diluted yeast total RNA, as indicated, was spiked into a fixed concentration (800 ng) of total HeLa RNA and analyzed by ePAT. The 200-ng sample was also used to prepare a TVN-PAT reaction. PCR amplicons from TVN-PAT and ePAT reactions were resolved on 2\% highresolution agarose gels and imaged. The TVN-PAT reaction represents the size of the amplicon with a fixed $\left(\mathrm{A}_{12}\right)$-tail. The signal intensity, but not the poly(A)-tail length distribution, of the two yeast genes GAL10 and APQ12 decreases with decreasing total RNA concentration. The human GAPDH adenylation state and concentration remains constant. (C) The signal from the GAL10 and APQ12 transcripts was quantitated by peak-finding and densitometry. The normalized signal (to $100 \% y$-axis) was plotted against concentration ( $x$-axis) and expressed in $\log _{2}$ to show the linear relationship between the signal and the RNA concentration.

range of the PCR reaction and the limits of fluorescence detection (Fig. 1C). The signal for APQ12 is linear over the entire dilution range $\left(\mathrm{r}^{2}=0.9975\right)$, whereas the GAL10 signal is quantitative between $100 \mathrm{ng}$ and $6 \mathrm{ng}$ input $\left(\mathrm{r}^{2}=\right.$ 0.9959). The signal from human GAPDH does not vary in response to a change in the concentration of spike in yeast total RNA.

We compared the efficacy of ePAT directly to the standard LM-PAT method that relies on serial ligation of $\mathrm{p}(\mathrm{dT})_{12-18}$ and an anchor primer to generate cDNA that encompasses the full poly(A)-tail (Salles and Strickland 1995). First, we compared the methods by generating a series of in vitro synthesized and adenylated TOM5 transcripts (Fig. 3A, see below; Supplemental Fig. A). The adenylated 
transcripts were spiked into total HeLa RNA to asses the accuracy of ePAT in length calling. By this approach, there was a good overall correlation between the average tail length of in vitro transcripts and the observed size of the ePAT amplification products. Specifically, in vitro transcripts with an estimated average poly(A)-tail length of $\sim 15, \sim 45, \sim 65$, and $\sim 115$ adenosine residues (see Supplemental Fig. A) showed an estimated poly(A)-tail length of $\sim 20, \sim 40, \sim 65$, and $\sim 95$ by ePAT. The estimation of the average tail length of both the in vitro transcripts and the PCR products is based on migration relative to RNA and DNA ladders, respectively, and is accurate to approximately $\pm 10 \mathrm{nt}$. Both assays reflect the length of the in vitro synthesized poly(A)-tail. However, the LM-PAT assay is slightly biased toward specific sizes, preferentially reporting the $\sim 45$-A transcripts and artifactually reporting a tail of this length in mRNA having longer poly(A)-tails.

Next, we monitored the adenylation state of specific endogenous transcripts in response to a transcriptional pulse chase regimen in Saccharomyces cerevisiae involving activation of gene expression by galactose followed by repression by the addition of glucose (Decker and Parker 1993; Beilharz and Preiss 2007). Yeast cells were harvested $10 \mathrm{~min}$ after galactose induction and at the indicated time points in the pulse period after glucose repression (Fig. 2B). At the point of transcriptional shutdown (glucose addition), the two 3' UTR isoforms of the GAL1 transcript had a long ( $\sim 50 \mathrm{~A})$ poly $(\mathrm{A})$-tail that shortened over time (Fig. 2C). Again, the two assays were equally efficient at generating cDNA that reflected the adenylation state of the transcripts. However, the ePAT assay provided a better reflection of the distribution of poly(A) tails in the sample. Because the LM-PAT assay depends on serial annealing of fixed length oligo-(pdT) oligonucleotides, only limited resolution can be achieved (see also Beilharz and Preiss [2009] for further discussion). We monitored the kinetics of deadenylation of both GAL1 3' UTR isoforms after transcriptional repression by densitometry and peak-identification (Fig. 1D). Linear deadenylation rates for both the GAL1 transcript isoforms were calculated from ePAT data. Such decay curves were previously only possible by highresolution Northern blots (Decker and Parker 1993). Therefore, compared to LM-PAT, the ePAT method provided a more accurate measurement of the poly(A)-tail length distribution and more detailed estimation of the deadenylation kinetics. It is important to note that the GAL1 transcript has previously been shown to undergo an additional nonstandard post-transcriptional cleavage and adenylation step to generate the GAL1-(short) transcript $\sim 10 \mathrm{~min}$ after glucose repression (Vodala et al. 2008). However, the similar initial length and decay kinetics of the poly(A)-tail at the start of the chase period in this experiment suggests that both forms were generated by the canonical transcript cleavage and adenylation machinery. Any additional cleavage products would remain invisible to the assay until they became adenylated.

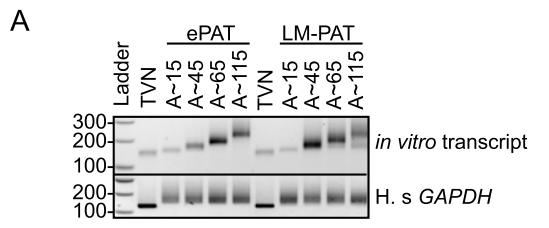

$\mathrm{B}$

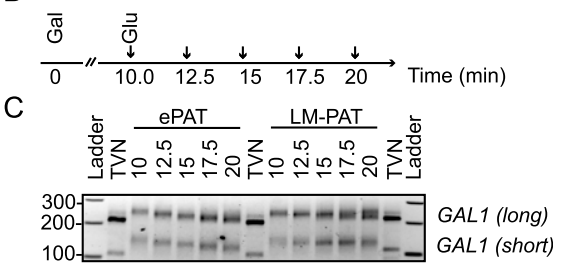

$\mathrm{D}$

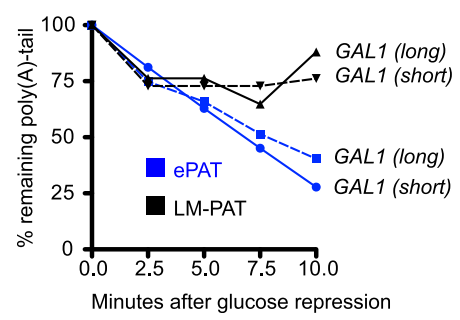

FIGURE 2. (A) Four in vitro synthesized and adenylated transcripts with the indicated average poly $(\mathrm{A})$-tail length were spiked into a fixed amount of total HeLa RNA (800 ng) and analyzed by ePAT and LMPAT (see Supplemental Material for details of in vitro transcripts). (B) Schematic representation of the time course of galactose induction and glucose repression. The arrows indicate the time points at which cells were harvested. (C) The 10-min time point represents newly synthesized GAL1 transcript with a long poly(A)-tail. The GAL1(long) and GAL1-(short) transcripts are generated by alternate poly(A) site usage. (D) The time-dependent shortening of the two GAL1 amplicons was quantified relative to the 100-bp ladder and the migration of the TVN product. This is only really possible using the ePAT assay, since laddering in the LM-PAT assay results in two peaks of similar intensity at the last time point of this assay $(20 \mathrm{~min})$.

\section{Alternate poly(A) site usage is revealed by ePAT}

Recent evidence has shown that the use of alternate poly(A) sites is widespread and dynamic in eukaryotic transcriptomes (Mangone et al. 2010; Ozsolak et al. 2010; Yoon and Brem 2010; Jan et al. 2011; Shepard et al. 2011; Wu et al. 2011). The use of shorter $3^{\prime}$ UTRs often provides a mechanism to remove the influence of post-transcriptional regulatory modules within $3^{\prime}$ UTRs, such as microRNA and regulatory protein binding sites (Sandberg et al. 2008). Since cDNA priming for ePAT requires extension of the $3^{\prime}$ end of the RNA molecule, internal poly(A) stretches are avoided. HXK1 is one of a number of genes, including GAL1 above, that change their subnuclear position in response to activation by galactose in a $3^{\prime}$ UTR-dependent manner, suggesting a role for $3^{\prime}$ processing in gene activation and/or repression (Abruzzi et al. 2006; Taddei et al. 2006; Vodala et al. 2008). In this study, we performed a transcriptional pulse chase (Fig. 3A) and found evidence for alternative polyadenylation of the HXK1 transcript. The HXK1-(long) transcript followed normal decay kinetics of 
A

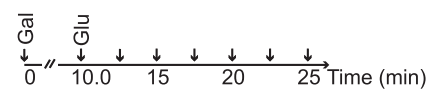

B

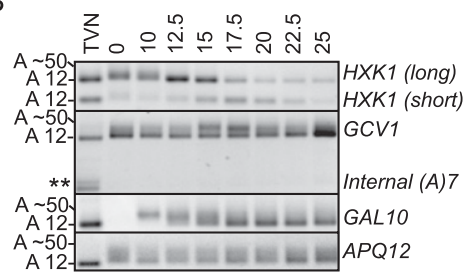

FIGURE 3. Alternate polyadenylation sites are revealed by ePAT. (A) Schematic representation of the time course of galactose induction and glucose repression. The arrows indicate the time points at which cells were harvested. (B) HXK1 transcription is rapidly repressed by glucose. During this repression phase, the ratio between HXK1-(long) and HXK1-(short) changes as the short 3' UTR form is transiently induced without a significant increase in poly(A)-tail length. GCV1 is transiently induced with a long poly(A)-tail by glucose addition. The faster migrating $G C V 1$ amplicon, indicated by ${ }^{* *}$, is likely a product of internal priming in the TVN reaction. The GAL10 and APQ12 panels are included as pulse-chase and ePAT assay controls, respectively.

deadenylation followed by decay of the transcript body after repression by glucose. The compaction of the PCR amplicons from a smear to a tight, short-tailed band explains the apparent increase of the HXK1-(long) transcript at 12.5 and $15 \mathrm{~min}$. In contrast, the abundance of HXK1(short) transcript transiently increased at $17.5 \mathrm{~min}$. This was similar to the observation of GAL1-(short) accumulation by a nonstandard cleavage and polyadenylation mechanism reported by Vodala et al. (2008). Sequencing of the two HXK1 PCR amplicons allowed for precise mapping of the alternate poly(A)-sites, located 65 and 175 bases after the stop codon for the short and long UTRs, respectively. This result suggests that a switch to the shorter UTR removes two of three canonical UGUA pumilio consensus sites previously identified as candidate Pufl sites in the $3^{\prime}$ UTR of HXK1 (Ulbricht and Olivas 2008). However, how this might influence Hxk1 protein expression remains unexplored. It is important to note that, in contrast to GAL1 and HXK1, the apparent shorter alternate 3' UTR of GCV1 suggested by the TVN-PAT reaction (see ** in Fig 3B) is likely an artifact, having a size consistent with internal priming to a 7-adenosine internal stretch within the GCV1 transcript. Thus, in contrast to oligo-dT-based priming methods, the ePAT approach allows identification of bona fide alternate poly(A) sites.

\section{3 '-tagging by ePAT is efficient}

An alternative method for measuring poly(A)-tail length has been the use of T4-ligase to append preadenylated linkers to the $3^{\prime}$ end of mRNA using methods analogous to those applied to the cloning of microRNA (Charlesworth et al. 2004; Kim et al. 2009) or circularization of mRNA
(Couttet et al. 1997; Rissland and Norbury 2009). These approaches are conceptually appealing in that they do not require knowledge of the bases that terminate the RNA of interest and can, therefore, be used to identify $3^{\prime}$ uridilation and other heteropolymeric $3^{\prime}$ extensions on RNA. The disadvantage of these methods is that they are inefficient and often require high PCR cycle numbers (commonly 40 cycles) and/or the use of radiolabeling to detect a product. To assess the performance of ePAT in applications where a T4-RNA ligation-based assay had been previously applied, we replicated the results presented by Kim et al. (2009), who elegantly demonstrated the dependence of several transcripts on the cytoplasmic deadenylase Gld-2 in the Caenorhabditis elegans germline. Using 10-fold less RNA input, twofold less cDNA, and 12 fewer cycles of PCR amplification (28 versus 40 ), the ePAT assay replicated and extended the data provided by Kim et al. (2009) (Fig. 4). RNA was isolated from wild-type Bristol Normal (N2) and gld-2 mutant worms. Two hundred ng of this was spiked into yeast total RNA and subject to ePAT. The adenylation state of egg-1, pup-2, and oma-2 were confirmed to depend on Gld-2, as does the germline specific gpd-4 (GAPDH). The steady-state poly(A)-tail length of somatic gpd-2 (GAPDH) and eft-3 were not significantly altered (data not shown).

To infer the efficiency of ePAT, we designed a PCR calculator that uses the PCR cycle number, an estimated PCR efficiency, and the amplicon length and mass in combination with the molecular weight of a DNA base pair to

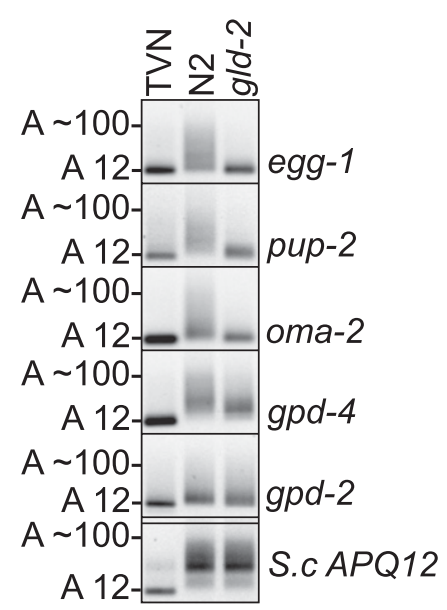

FIGURE 4. The cytoplasmic poly(A)-polymerase Gld-2 is required for normal adenylation of transcripts in the C. elegans germline. The adenylation state of four maternal mRNA egg-1, Pup-2, oma-2, and $g p d-4$ was analyzed in Bristol Normal (N2) and gld-2 mutant worms. In each case, the mRNA is short-tailed in the mutant, which reflects the inactive state. The adenylation state of the somatic transcript $g p d-2$ is not affected in a major way by the loss of Gld-2. Yeast total RNA (800 ng) from a deadenylase-deficient mutant (pan $2 \Delta / c c r 4-1)$ was spiked into the assay as ballast for the low concentration of worm RNA (200 ng). The yeast APQ12 panel is included to demonstrate equal ePAT efficiency across samples. 
estimate the number of cDNA input molecules that contribute to the final PCR product (Supplemental File 2). For example, at least 5000 template egg- $1 \mathrm{cDNA}$ molecules in the PCR reaction mix were required to generate $110 \mathrm{ng}$ of the 120-bp PCR amplicon as measured by densitometry (Fig. 4, gld-2). If 40 cycles of amplification had been required to generate this amount of product, then the number of contributing cDNA molecules would reduce to approximately two. Thus, with every additional PCR cycle necessary to produce detectable product, there is an increased risk of biased sampling. Interestingly, using ePAT, we observed a tail-length distribution of $\sim 12-100$ A-residues for most transcripts in wild-type (N2) worms, which was a striking difference to that observed by Kim et al. (2009). Using the ligation approach and 40 cycles of amplification, Kim et al. (2009) reported a uniform tail length of $\sim 40$ bases for oma-2. The length was significantly reduced in gld-2 mutant worms as measured by both studies. Taken together, we have shown that the ePAT approach returns similar and possibly more detailed information on poly(A) status than T4-ligase-based approaches and at significantly higher efficiency.

\section{CONCLUSION}

In this study, we describe a simple method to tag adenylated RNA within a population and demonstrate its use for the identification of alternate $3^{\prime}$ UTRs and measurement of the poly(A)-tail length of mRNA. The method is quantitative within the linear range of amplification and can be applied to detect transcripts from very low concentrations of RNA. This approach is the closest method described to date that matches the sensitivity observed by high-resolution Northern blot but avoids radiolabeled probes, requires a fraction of the time and RNA input, and generates enough cDNA for analysis of over 20 specific transcripts from a single ePAT reaction. Moreover, all of the necessary components are standard in any molecular biology laboratory.

\section{MATERIALS AND METHODS}

\section{Saccharomyces cerevisiae}

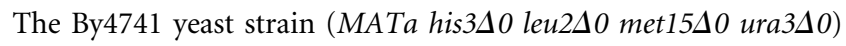
was grown to exponential phase (OD600 0.6) in rich medium ( $2 \%$ peptone and $1 \%$ yeast extract) with $2 \%$ raffinose as the sole carbon source. Transcription of GAL genes were transiently induced by addition of $2 \%$ galactose and then repressed after $10 \mathrm{~min}$ by the addition of $2 \%$ glucose. At each indicated time point, $5 \mathrm{~mL}$ of culture was removed into $15 \mathrm{~mL}$ tubes containing $50 \mu \mathrm{L} 10 \%$ sodium azide prechilled in an ice bath. Once all samples were collected, the cells were harvested by centrifugation (4000 $g$ for $2 \mathrm{~min}$ ), washed once in ice-cold water containing sodium azide $(0.1 \%)$, snap frozen, and stored at $-80^{\circ} \mathrm{C}$.

\section{Caenorhabditis elegans}

C. elegans wild-type Bristol N2 and gld-2(q497) strains were maintained at $20^{\circ} \mathrm{C}$ using standard methods (Brenner 1974).

\section{RNA extraction}

Total RNA from yeast cells was prepared according to the hot phenol method. Total C. elegans RNA was prepared by suspending between 50 and 100 snap frozen worms in $1 \mathrm{~mL}$ of Trizol (Life Technologies). After addition of $\sim 200 \mu \mathrm{L}$ ziconia beads (Biospec Products), the sample was homogenized for $30 \mathrm{sec}$ using a MiniBeadbeater 8 (Biospec Products). Trizol extraction was performed according to the manufacturer's instructions, except that $2 \mu \mathrm{L}$ glycogen was added prior to precipitation with isopropanol. To improve the generally poor Nano-drop QC A260/A230 ratios that result from Trizol purifications, we resuspended the resulting pellet in $100 \mu \mathrm{L} \mathrm{dH_{2 }} \mathrm{O}$ and reprecipitated the RNA with $1 / 10$ volume of $3 \mathrm{M} \mathrm{NaOac}[\mathrm{pH} 5.2]$ and 2.5 volumes of ethanol. RNA quantification was performed with a Nano-Drop 1000 (Thermo Scientific).

\section{The ePAT method and product detection}

The ePAT approach uses the same PAT-anchor primer that has been described for the LM-PAT method (PAT anchor 5'-GCGAGCTCCGCGGCCGCGTTTTTTTTTTTT), which was stored as small $100-\mu \mathrm{M}$ aliquots at $-20^{\circ} \mathrm{C}$. Of note, alternative anchor sequences were equally efficient in our laboratory. The incubation steps of the assay were most conveniently performed in a thermocycler with an accessible lid programmed with a series of temperature hold/pause settings, where the pause maintains temperature while allowing access to the tubes.

To assemble the ePAT reaction, $1 \mu \mathrm{g}$ of total RNA (or less) and $1 \mu \mathrm{L}$ of PAT-anchor primer were combined and brought to a volume of $8 \mu \mathrm{L}$ with $\mathrm{dH}_{2} \mathrm{O}$ in a $200-\mu \mathrm{L}$ PCR tube. The mixture was incubated at $80^{\circ} \mathrm{C}$ for $5 \mathrm{~min}$ and then cooled to room temperature. Once cooled, the sample was flash-centrifuged, and

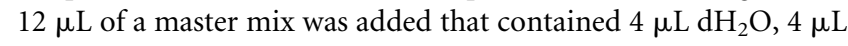
$5 \times$ Superscript III buffer (Life Technologies), $1 \mu \mathrm{L} 100 \mathrm{mM}$ DTT, $1 \mu \mathrm{L} 10 \mathrm{mM}$ dNTPs, $1 \mu \mathrm{L}$ RNaseOUT (Life Technologies), and $1 \mu \mathrm{L}$ ( $5 \mathrm{U}$ ) Klenow polymerase (New England Biolabs) per reaction. The sample was mixed thoroughly by inversion, flash-centrifuged, and then incubated at $25^{\circ} \mathrm{C}$ for $1 \mathrm{~h}$. Importantly, $37^{\circ} \mathrm{C}$ worked equally well in our laboratory and may improve selectivity. The polymerase was then inactivated by increasing the temperature to $80^{\circ} \mathrm{C}$ for $10 \mathrm{~min}$ prior to cooling the reaction to $55^{\circ} \mathrm{C}$ for $1 \mathrm{~min}$. While maintaining the tubes at that temperature in the block, $1 \mu \mathrm{L}$ (200 U) of Superscript III (Life Technologies) was added to the tubes. The tubes were closed and mixed rapidly by flick-inversion. Incubation was then resumed at $55^{\circ} \mathrm{C}$ for $1 \mathrm{~h}$, followed by inactivation of the reverse transcriptase by increasing the temperature to $80^{\circ} \mathrm{C}$ for $10 \mathrm{~min}$. It is critical to maintain the temperature during the reverse transcription step because internal priming can occur if the temperature drops. At $55^{\circ} \mathrm{C}$, only priming from an end-extended RNA molecule is possible. It can also be useful to include spiked-in RNA from an unrelated organism as ballast for dilute RNA reactions and to control for equal assay efficiency across samples. We routinely spike total HeLa RNA in yeast samples and RNA from a deadenylase deficient yeast strain in metazoan RNA samples. 
For the PCR reactions, CDNA was diluted 1:6 by the addition of $120 \mu \mathrm{L} \mathrm{dH_{2 }}$ O. The PCR reactions were typically conducted in a total volume of $20 \mu \mathrm{L}$ using $5 \mu \mathrm{L}$ of diluted cDNA input and a fast-start polymerase, such as Fast-Start (Roche) or Amplitaq Gold 360 master (Life Technologies). It can also be useful to include a TVN-PAT reaction as a size control for the size of the amplicon with a fixed A12 poly(A)-tail. Both the LM-PAT and the TVN-PAT reactions were performed exactly as described previously (Beilharz and Preiss 2009). The cycle number was dependent on the abundance of the transcript of interest in the sample but normally ranges between $23-33$ cycles.

To detect the PCR amplicons from TVN-PAT, ePAT, and LMPAT PCR reactions, $50 \%$ of a $20-\mu \mathrm{L}$ PCR reaction was loaded per lane into a 2\% high-resolution agarose gel (Ultra pure 1000; Life Technologies) that was prestained with SYBR safe (Life Technologies). The primers used in this study are supplied (Supplemental File 1). To estimate the PCR product sizes and to quantify the mass of PCR amplicons from such gels, the band intensity and migration was determined relative to a 100-bp ladder (New England Biolabs) using an LAS 3000 imager and multigauge software (Fujifilm). To track deadenylation kinetics, the migration of the highest peak intensity of each band was determined for each lane and expressed relative to the migration of the TVN-PAT peak. The length of $\operatorname{poly}(\mathrm{A})$ at time zero was then normalized to $100 \%$, and the peaks of subsequent time points were expressed relative to the normalized control. Using this approach in Figure 2, highly linear $\left[\mathrm{R}^{2}=0.9997\right.$ and 0.9682 for GAL1-(long) and GAL1-(short), respectively] deadenylation curves were possible from ePAT samples but not LM-PAT samples $\left[\mathrm{R}^{2}=0.1751\right.$ and 0.4049 for GAL1-(long) and GAL1-(short), respectively]. The graphs and statistical analyses were prepared using GraphPad Prism software.

Efficiency calculations used to estimate the number of cDNA input molecules were based on a calculated mass of $110 \mathrm{ng}$ and an amplicon length of 120-bp at an estimated efficiency of $98 \%$ as user inputs for oma-2 in the PCR calculator (Supplemental File 2).

\section{SUPPLEMENTAL MATERIAL}

Supplemental material is available for this article.

\section{ACKNOWLEDGMENTS}

We thank members of the Beilharz, Traven, and Boag labs for critical reading of the manuscript and Trevor Lithgow for the TOM5 in vitro transcription plasmid. T.B. is supported by an Australian Research Council Fellowship (DP0878224). Work on C. elegans germline development in the P.B. laboratory is supported by NHMRC project grant (606575). Work on the PUF RNA binding proteins in the A.T. laboratory is supported by an ARC Discovery project (DP1092850).

Received December 12, 2011; accepted March 7, 2012.

\section{REFERENCES}

Abruzzi KC, Belostotsky DA, Chekanova JA, Dower K, Rosbash M. 2006. $3^{\prime}$-end formation signals modulate the association of genes with the nuclear periphery as well as mRNP dot formation. EMBO J 25: 4253-4262.
Beilharz TH, Preiss T. 2007. Widespread use of poly(A) tail length control to accentuate expression of the yeast transcriptome. RNA 13: 982-997.

Beilharz TH, Preiss T. 2009. Transcriptome-wide measurement of mRNA polyadenylation state. Methods 48: 294-300.

Beilharz TH, Humphreys DT, Clancy JL, Thermann R, Martin DI, Hentze MW, Preiss T. 2009. microRNA-mediated messenger RNA deadenylation contributes to translational repression in mammalian cells. PLoS ONE 4: e6783. doi: 10.1371/journal.pone.0006783.

Brenner S. 1974. The genetics of Caenorhabditis elegans. Genetics 77: 71-94.

Brown CE, Sachs AB. 1998. Poly(A) tail length control in Saccharomyces cerevisiae occurs by message-specific deadenylation. Mol Cell Biol 18: 6548-6559.

Burns DM, D'Ambrogio A, Nottrott S, Richter JD. 2011. CPEB and two poly(A) polymerases control miR-122 stability and p53 mRNA translation. Nature 473: 105-108.

Charlesworth A, Cox LL, MacNicol AM. 2004. Cytoplasmic polyadenylation element (CPE)- and CPE-binding protein (CPEB)independent mechanisms regulate early class maternal mRNA translational activation in Xenopus oocytes. J Biol Chem 279: 17650-17659.

Couttet P, Fromont-Racine M, Steel D, Pictet R, Grange T. 1997. Messenger RNA deadenylylation precedes decapping in mammalian cells. Proc Natl Acad Sci 94: 5628-5633.

Dagley MJ, Gentle IE, Beilharz TH, Pettolino FA, Djordjevic JT, Lo TL, Uwamahoro N, Rupasinghe T, Tull DL, McConville M, et al. 2011. Cell wall integrity is linked to mitochondria and phospholipid homeostasis in Candida albicans through the activity of the post-transcriptional regulator Ccr4-Pop2. Mol Microbiol 79: 968989.

Decker CJ, Parker R. 1993. A turnover pathway for both stable and unstable mRNAs in yeast: Evidence for a requirement for deadenylation. Genes Dev 7: 1632-1643.

Eckmann CR, Rammelt C, Wahle E. 2011. Control of poly(A) tail length. Wiley Interdiscip Rev RNA 2: 348-361.

Eulalio A, Huntzinger E, Nishihara T, Rehwinkel J, Fauser M, Izaurralde E. 2009. Deadenylation is a widespread effect of miRNA regulation. RNA 15: 21-32.

Fabian MR, Mathonnet G, Sundermeier T, Mathys H, Zipprich JT, Svitkin YV, Rivas F, Jinek M, Wohlschlegel J, Doudna JA, et al. 2009. Mammalian miRNA RISC recruits CAF1 and PABP to affect PABP-dependent deadenylation. Mol Cell 35: 868-880.

Huang Z, Szostak JW. 1996. A simple method for 3'-labeling of RNA. Nucleic Acids Res 24: 4360-4361.

Jan CH, Friedman RC, Ruby JG, Bartel DP. 2011. Formation, regulation and evolution of Caenorhabditis elegans 3'UTRs. Nature 469: 97-101.

Kim KW, Nykamp K, Suh N, Bachorik JL, Wang L, Kimble J. 2009. Antagonism between GLD-2 binding partners controls gamete sex. Dev Cell 16: 723-733.

Lackner DH, Beilharz TH, Marguerat S, Mata J, Watt S, Schubert F, Preiss T, Bahler J. 2007. A network of multiple regulatory layers shapes gene expression in fission yeast. Mol Cell 26: 145-155.

Mangone M, Manoharan AP, Thierry-Mieg D, Thierry-Mieg J, Han T, Mackowiak SD, Mis E, Zegar C, Gutwein MR, Khivansara V, et al. 2010. The landscape of $C$. elegans 3'UTRs. Science 329: 432-435.

Okazaki T, Okazaki R. 1969. Mechanism of DNA chain growth. IV. Direction of synthesis of T4 short DNA chains as revealed by exonucleolytic degradation. Proc Natl Acad Sci 64: 1242-1248.

Ozsolak F, Kapranov P, Foissac S, Kim SW, Fishilevich E, Monaghan AP, John B, Milos PM. 2010. Comprehensive polyadenylation site maps in yeast and human reveal pervasive alternative polyadenylation. Cell 143: 1018-1029.

Proudfoot NJ, Furger A, Dye MJ. 2002. Integrating mRNA processing with transcription. Cell 108: 501-512.

Rissland OS, Norbury CJ. 2009. Decapping is preceded by 3' uridylation in a novel pathway of bulk mRNA turnover. Nat Struct Mol Biol 16: 616-623. 
Rouhana L, Wickens M. 2007. Autoregulation of GLD-2 cytoplasmic poly(A) polymerase. RNA 13: 188-199.

Sachs AB, Varani G. 2000. Eukaryotic translation initiation: There are (at least) two sides to every story. Nat Struct Biol 7: 356-361.

Salles FJ, Strickland S. 1995. Rapid and sensitive analysis of mRNA polyadenylation states by PCR. PCR Methods Appl 4: 317-321.

Sandberg R, Neilson JR, Sarma A, Sharp PA, Burge CB. 2008. Proliferating cells express mRNAs with shortened $3^{\prime}$ untranslated regions and fewer microRNA target sites. Science 320: 1643-1647.

Sheets MD, Fox CA, Hunt T, Vande Woude G, Wickens M. 1994. The $3^{\prime}$-untranslated regions of c-mos and cyclin mRNAs stimulate translation by regulating cytoplasmic polyadenylation. Genes Dev 8: $926-938$.

Shepard PJ, Choi EA, Lu J, Flanagan LA, Hertel KJ, Shi Y. 2011. Complex and dynamic landscape of RNA polyadenylation revealed by PAS-Seq. RNA 17: 761-772.

Sippel AE, Stavrianopoulos JG, Schutz G, Feigelson P. 1974. Translational properties of rabbit globin mRNA after specific removal of poly(A) with ribonuclease H. Proc Natl Acad Sci 71: 4635-4639.

Slomovic S, Fremder E, Staals RH, Pruijn GJ, Schuster G. 2010. Addition of poly(A) and poly(A)-rich tails during RNA degradation in the cytoplasm of human cells. Proc Natl Acad Sci 107: 74077412.

Taddei A, Van Houwe G, Hediger F, Kalck V, Cubizolles F, Schober H, Gasser SM. 2006. Nuclear pore association confers optimal expression levels for an inducible yeast gene. Nature 441: 774-778.

Traven A, Beilharz TH, Lo TL, Lueder F, Preiss T, Heierhorst J. 2009. The Ccr4-Pop2-NOT mRNA deadenylase contributes to septin organization in Saccharomyces cerevisiae. Genetics 182: 955-966.

Ulbricht RJ, Olivas WM. 2008. Puflp acts in combination with other yeast Puf proteins to control mRNA stability. RNA 14: $246-$ 262.

Vodala S, Abruzzi KC, Rosbash M. 2008. The nuclear exosome and adenylation regulate posttranscriptional tethering of yeast GAL genes to the nuclear periphery. Mol Cell 31: 104-113.

Wu X, Liu M, Downie B, Liang C, Ji G, Li QQ, Hunt AG. 2011. Genome-wide landscape of polyadenylation in Arabidopsis provides evidence for extensive alternative polyadenylation. Proc Natl Acad Sci 108: 12533-12538.

Yoon OK, Brem RB. 2010. Noncanonical transcript forms in yeast and their regulation during environmental stress. RNA 16: 12561267. 

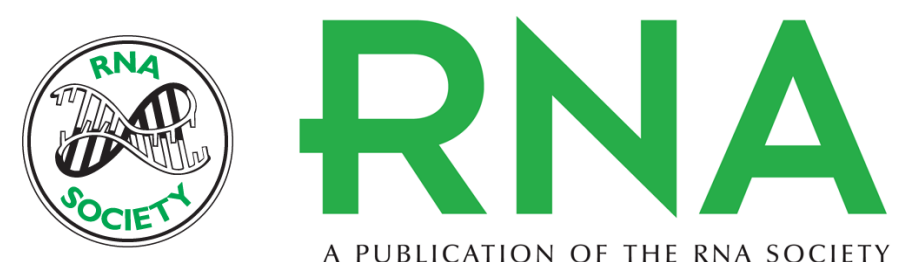

A PUBLICATION OF THE RNA SOCIETY

\section{ePAT: A simple method to tag adenylated RNA to measure poly(A)-tail length and other 3 ' RACE applications}

Amrei Jänicke, John Vancuylenberg, Peter R. Boag, et al.

RNA 2012 18: 1289-1295 originally published online April 27, 2012

Access the most recent version at doi:10.1261/rna.031898.111

\section{Supplemental http://rnajournal.cshlp.org/content/suppl/2012/03/29/rna.031898.111.DC1 Material}

References This article cites 37 articles, 17 of which can be accessed free at: http://rnajournal.cshlp.org/content/18/6/1289.full.html\#ref-list-1

\section{License}

Email Alerting Receive free email alerts when new articles cite this article - sign up in the box at the Service top right corner of the article or click here.

To subscribe to RNA go to:

http://rnajournal.cshlp.org/subscriptions 